\title{
Influence of Zirconia Incorporation on the Mechanical and Chemical Properties of Ni-Co Alloys
}

\author{
Meenu Srivastava*, A Srinivasan, V K William Grips
}

Surface Engineering Division, Council of Scientific and Industrial Research, National Aerospace Laboratories, Bangalore, 560017, India

\begin{abstract}
Ni-Co- $\mathrm{ZrO}_{2}$ nano-composites are electrodeposited from sulphamate electrolyte and a comparison is made with $\mathrm{Ni}-\mathrm{ZrO}_{2}$ in terms of structure and properties. The Co content in the coatings is in the range of $10-80 \mathrm{wt} \%$. The deposition conditions like current density, $\mathrm{pH}$ are optimized in terms of microhardness and amounts of $\mathrm{ZrO}_{2}$ incorporated. The microhardness studies revealed that the maximum hardness is exhibited by Ni-28Co- $2 \mathrm{ZrO}_{2}$ composite. The FESEM study showed a change in morphology from polyhedral to ridge with increase in Co content from 10 to $80 \mathrm{wt} \%$. A change in crystal structure from fcc to hcp is also seen. The effect of annealing treatment in terms of microhardness is studied by subjecting the composite electroforms to $800^{\circ} \mathrm{C}$. The Co rich composite exhibited better stability compared to $\mathrm{Ni}$ rich composites. $\mathrm{Ni}-28 \mathrm{Co}-2 \mathrm{ZrO}_{2}$ composite exhibited better immersion corrosion resistance while, $\mathrm{Ni}-\mathrm{ZrO}_{2}$ composite displayed better electrochemical corrosion resistance. The wear studies showed that $\mathrm{Ni}-10 \mathrm{Co}-2 \mathrm{ZrO}_{2}, \mathrm{Ni}-28 \mathrm{Co}-2 \mathrm{ZrO}_{2}$ composites showed better resistance. Thus, it is seen that the coatings can be tailored to suit various applications.
\end{abstract}

Keywords Metal matrix composites, Ni-Co-ZrO ${ }_{2}$, Tribology, Wear, Corrosion, Electrochemical Study

\section{Introduction}

Corrosion and wear destroy national wealth in multibillion dollar range annually. Modern high performance components are subjected to extreme temperatures and mechanical stress, and thus require surface protection against high temperature and mechanical wear and tear. A highly versatile and low cost technique must be selected to apply protective coatings, one such technique is electroplating. ${ }^{1}$ Composite electroplating involves the co-deposition of insoluble metallic or non-metallic compounds in a metal or alloy matrix. Such composite coating features the properties of both the matrix and the dispersed phase. The coatings are called as metal matrix composites (MMC) when the matrix involved is a metal. Composite coatings comprising of various dispersed phases like $\mathrm{SiC}, \mathrm{Si}_{3} \mathrm{~N}_{4}, \mathrm{Al}_{2} \mathrm{O}_{3}, \mathrm{CeO}_{2}, \mathrm{TiO}_{2}$, YSZ etc have been developed for diverse applications. ${ }^{2-10}$ The composite system considered in the present study comprises of $\mathrm{Ni}-\mathrm{Co}$ alloy as the matrix. The benefit of choosing Ni-Co alloy as matrix lies in the fact that alloying of $\mathrm{Ni}$ with Co strengthens it by forming a solid solution which helps to improve wear, corrosion resistance and also improves the high temperature properties. $^{11,12}$ The dispersed phase chosen is zirconia $\mathrm{ZrO}_{2}$, as it is known to possess excellent properties such as

* Corresponding author:

meenusri@nal.res.in (Meenu Srivastava)

Published online at http://journal.sapub.org/materials

Copyright (C) 2011 Scientific \& Academic Publishing. All Rights Reserved mechanical strength, chemical inertness, thermal stability, wear and corrosion resistance. ${ }^{13}$ Its good thermal matching with metals makes it suitable for protective coatings. ${ }^{14,15}$ It is also a promising constituent present in the transition metal based catalysts used in exhaust gas purifying devices. ${ }^{16}$ Depending on its crystalline structure it can be an insulator used as high resistance ceramic or an n-type semiconductor. ${ }^{15} \mathrm{ZrO}_{2}$ exists as a polymorph, namely cubic, tetragonal and monoclinic. ${ }^{17}$ The effect of incorporation of $\mathrm{ZrO}_{2}$ in $\mathrm{Ni}$ matrix has been extensively reported. ${ }^{13,18-24}$ Reddy et al have reinforced tetragonal $\mathrm{ZrO}_{2}$ in Ni matrix by pulsed electrodeposition. A $16 \%$ increase in microhardness of the composite has been reported. ${ }^{23}$ The composite on annealing $\left(50-200^{\circ} \mathrm{C}\right)$ showed an increase in the microhardness followed by a substantial decrease upto $300^{\circ} \mathrm{C}$. Effect of heat treatment on the incorporation of $\mathrm{ZrO}_{2}$ in Ni-Co matrix has not been studied much. ${ }^{25}$ Zhang et al have reported brush plating of $\mathrm{Ni}-\mathrm{Co}-\mathrm{ZrO}_{2}$ composite coating to repair the wear surface of the die casting dies of H13.The coating improved the surface hardness, wear resistance and oxygen resistance of dies.

The present study is aimed at incorporating $\mathrm{ZrO}_{2}$ nano-particles in Ni-Co alloy matrices by electrodeposition method, and studying its influence on the thermal, mechanical and chemical properties.

\section{Experimental}

The $\mathrm{Ni} / \mathrm{Ni}-\mathrm{Co}-\mathrm{ZrO}_{2}$ nano-composites were electroformed from a conventional additive free sulphamate electrolyte of 
composition Nickel sulphamate $275 \mathrm{~g} \mathrm{~L}^{-1}$, nickel chloride $6 \mathrm{gL}^{-1}$, boric acid $30 \mathrm{gL}^{-1}$ and SLS $0.2 \mathrm{gL}^{-1}$. Co was added as cobalt sulphamate and the additions were made so as to obtain Co content in the range of $10-80 \mathrm{wt} \% . \mathrm{ZrO}_{2}$ particles of size $20-30 \mathrm{~nm}$ and monoclinic crystal structure were procured from $\mathrm{M} / \mathrm{s}$ Nanostructured and Amorphous Materials, USA were used in this study. Particle content of $25 \mathrm{gL}^{-1}$ was dispersed in the electrolyte by magnetic stirring for a period of $16 \mathrm{hrs}$ prior to electrodeposition. The Ni-Co- $\mathrm{ZrO}{ }_{2}$ composites were deposited galvanostatically under ambient conditions using optimized conditions of $\mathrm{pH} 4.0$ and current density $0.8 \mathrm{Adm}^{-2}$. The coating was deposited on a mild steel substrate (cathode) of plating dimension $0.05 \mathrm{mX} 0.0375 \mathrm{~m}$ using Ni sheet as anode of size $0.05 \mathrm{mX} 0.05 \mathrm{~m}$. During the process of electrodeposition, the $\mathrm{ZrO}_{2}$ nano-particles were kept under suspension by magnetic stirring at a speed of 400rpm. The composite coatings were prepared metallographically and subjected to microhardness testing. The hardness was tested using the Knoop's indenter (Buehler Microhardness tester Micromet 100) employing a load of $0.050 \mathrm{kgf}$. The readings reported are the average of various measurements performed at different locations. The uniformity of $\mathrm{ZrO}_{2}$ distribution was analyzed using optical microscopy. The surface morphology of the coatings was studied using Field Emission Scanning Electron Microscope (FESEM), Carl Zeiss Supra $40 \mathrm{VP}$ and $\mathrm{ZrO}_{2}$, Co content in the coatings was determined using Energy Dispersive X- ray analysis (EDX).The crystal structure and the phases were identified using X-ray diffraction (XRD) studies. The crystallite size of the coatings was determined using Scherer formula $\mathrm{D}=\mathrm{K} \lambda(\beta \cos \theta)^{-1}$ where, $\mathrm{K}$ is the Scherrer factor $\approx 1$, $\mathrm{D}$ the crystallite size, $\lambda$ the incident radiation wavelength, $\beta$ is the integral breadth of the structurally broadened profile and $\theta$ is the angular position. ${ }^{26}$ The thermal stability of the coatings was studied by subjecting the composite electroforms to isothermal annealing at temperatures ranging from $200^{\circ} \mathrm{C}-800^{\circ} \mathrm{C}$ in intervals of $200^{\circ} \mathrm{C}$ for a duration of 1 hour. The thermal stability has been expressed in terms of microhardness. The corrosion resistance of the coatings was determined by immersion method and also by electrochemical polarization technique. The immersion test has been performed by immersing the composite electroforms in 3.5\% $\mathrm{NaCl}$ medium for $168 \mathrm{hrs}$ and the corrosion rate is expressed in terms of weight loss. A comparison was made with polarization and electrochemical impedance studies. These studies were carried out in a conventional three-electrode corrosion cell using a CHI604 2D (CH Instruments) test system. In the tests, specimen of area $1 \mathrm{~cm}^{2}$ was exposed to the electrolyte $(3.5 \% \mathrm{NaCl})$. The saturated calomel electrode was used as a reference, and platinum served as a counter electrode. The tests were performed under room temperature conditions. Prior to the experiment the samples were immersed in the electrolyte for $45 \mathrm{mins}$ to attain the open circuit potential (OCP) or steady state potential. After the stabilization of OCP the upper and lower potential limits were fixed to $\pm 200 \mathrm{mV}$ with respect to the OCP for carrying out the polarization studies. The Impedance measurements were performed in the frequency range of $10 \mathrm{~m} \mathrm{~Hz}$ to $100 \mathrm{kHz}$ and an amplitude of $10 \mathrm{mV}$ was applied on the OCP. All the measured data are presented as Nyquist and Bode plots. The wear resistance of the coatings has been analyzed under dry sliding conditions using Pin-on-disc wear tester (DUCOM India) and wear rate is expressed in terms of wear volume loss. The wear testing conditions are discussed in detail elsewhere. ${ }^{27}$ The volumetric wear loss $\mathrm{V}$ was determined using the equation: $\mathrm{V}=\pi \mathrm{h}^{2}(\mathrm{r}-\mathrm{h} / 3){ }^{17}$ where $\mathrm{r}$ is the radius of the hemispherical pin and $h$ is the wear height loss of the pin.

\section{Results and Discussion}

\section{1. $\mathrm{Ni}-\mathrm{ZrO}_{2}$ Co-deposition}

The deposition conditions were optimized with reference to $\mathrm{Ni}-\mathrm{ZrO}_{2}$ composite coating in terms of microhardness. The $\mathrm{pH}$ was varied in the range of 2.5 to 4.5 and the current density in the range of 0.8 to $6.4 \mathrm{Adm}^{-2}$. The variation in microhardness and the extent of $\mathrm{ZrO}_{2}$ incorporation ( $\left.\mathrm{Vol} \%\right)$ in the coating with respect to $\mathrm{pH}$ are shown in Figure1.

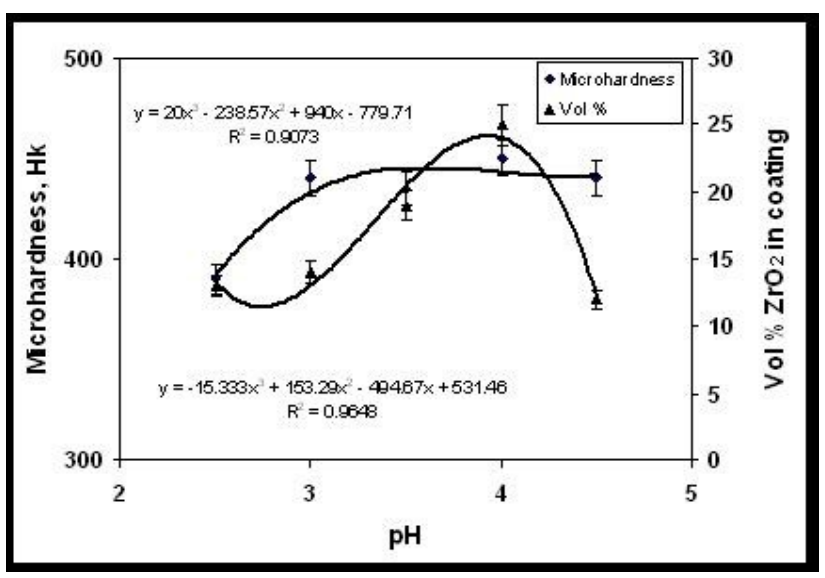

Figure 1. Correlation between $\mathrm{pH}$ and Microhardness, $\mathrm{Vol} \%$ of $\mathrm{ZrO}_{2}$ incorporated in the coating

It is seen from the figure that the equation that fits best between $\mathrm{pH}$, microhardness and $\mathrm{Vol} \%$ of $\mathrm{ZrO}_{2}$ incorporated is a third order polynomial of the form $\mathrm{y}=\mathrm{Ax}^{3}+\mathrm{Bx}^{2}+\mathrm{Cx}+\mathrm{k}$ where $\mathrm{y}$ represents the microhardness, $\mathrm{Hk}_{50 \mathrm{gf}}$ and $\mathrm{Vol} \%$ of $\mathrm{ZrO}_{2}$ incorporated in the coating while $\mathrm{x}$ is the $\mathrm{pH}$ of the electrolyte. A, B, C and $\mathrm{k}$ are the deposition constants specific to the composite system being electrodeposited. The constants were calculated from the experimental data by means of a regression program and they are given in Table 1.

Table 1. Constants and the correlation coefficient between Microhardness of the coating and $\mathrm{pH}$ of the electrolyte

\begin{tabular}{|c|c|c|c|c|c|}
\hline & $\mathrm{A}$ & $\mathrm{B}$ & $\mathrm{C}$ & $\mathrm{k}$ & $\mathrm{R}^{2}$ \\
\hline $\begin{array}{c}\text { Microhardness, } \\
\mathrm{Hk}\end{array}$ & 20 & -238.57 & 940 & -779.71 & 0.9073 \\
\hline $\begin{array}{c}\text { Vol \% of } \mathrm{ZrO}_{2} \\
\text { incorporation }\end{array}$ & -15.333 & 153.29 & -494.67 & 531.46 & 0.9648 \\
\hline
\end{tabular}

The correlation coefficient $\mathrm{R}^{2}$ has been found to be greater than 0.90 which conveys that the experimental data is in good agreement with the equation. The maximum micro- 
hardness (450Hk) and percentage of incorporation is seen for a $\mathrm{pH}$ value of 4.0 , hence, further studies have been confined to this $\mathrm{pH}$. Xiaozhen et al have reported similar results for

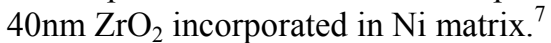

The influence of current density on the extent of $\mathrm{ZrO}_{2}$ incorporation and also on the microhardness is shown in Figure2. It is seen from the figure that the best fitting relation is a second order polynomial of the form $y=a x^{2}-b x+c$ with a correlation coefficient greater than 0.95 .

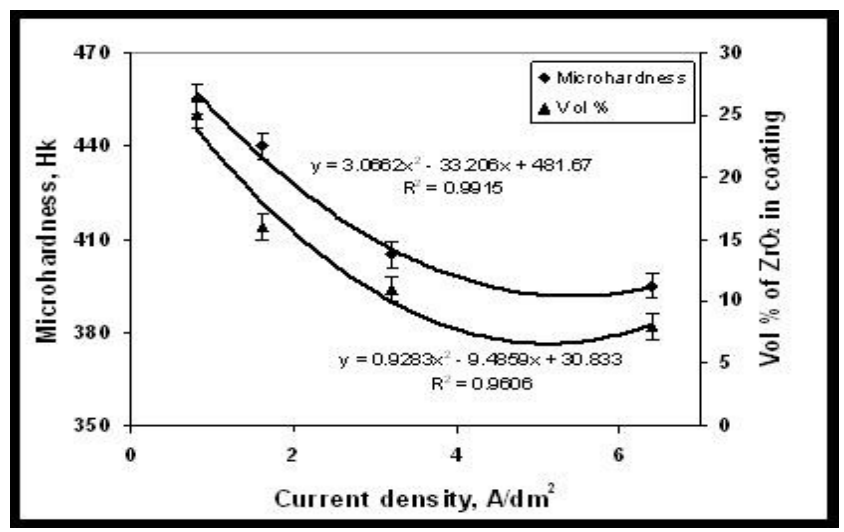

Figure 2. Influence of current density on Microhardness and $\mathrm{Vol} \%$ of $\mathrm{ZrO}_{2}$ incorporated in the coating

This shows that the experimental data is in good agreement with the polynomial equation. Here y is the microhardness and $\mathrm{Vol} \%$ of $\mathrm{ZrO}_{2}$ incorporated in the coating, $\mathrm{x}$ is the current density, $\mathrm{Adm}^{-2}$ and $\mathrm{a}, \mathrm{b}$ and $\mathrm{c}$ are the constants whose values are mentioned in Table 2 .

Table 2. Constants and the correlation coefficient between Microhardness of the coating and applied current density

\begin{tabular}{|c|c|c|c|c|}
\hline & $\mathrm{a}$ & $\mathrm{b}$ & $\mathrm{c}$ & $\mathrm{R}^{2}$ \\
\hline Microhardness, $\mathrm{Hk}$ & 3.0662 & -33.206 & 481.67 & 0.9915 \\
\hline $\begin{array}{c}\text { Vol \% of } \mathrm{ZrO}_{2} \\
\text { incorporation }\end{array}$ & 0.9283 & -9.4859 & 30.833 & 0.9606 \\
\hline
\end{tabular}

A mathematical correlation between current density and $\mathrm{ZrO}_{2}$ content in the coating has been reported by Benea et al. ${ }^{18}$ The maximum microhardness as well as $\mathrm{ZrO}_{2}$ incorporation is seen for a low current density of $0.8 \mathrm{Adm}^{-2}$ hence, the $\mathrm{Ni}-\mathrm{ZrO}_{2}$ and $\mathrm{Ni}-\mathrm{Co}-\mathrm{ZrO}_{2}$ nano-composite electroforming was carried out at $\mathrm{pH} 4.0$ and current density of $0.8 \mathrm{Adm}^{-2}$. This observation can be associated with the fact that during electrodeposition at lower current density $\left(0.8 \mathrm{Adm}^{-2}\right)$, the number of collisions between the particles and the cathode surface per unit volume of deposited matrix increases, thus allowing more particles to be incorporated into the coating. Similar observation has been made by Banovic et al for $\mathrm{Ni}-\mathrm{Al}_{2} \mathrm{O}_{3}$ composites. ${ }^{28}$ The current efficiency was seen to be in the range of $94-98 \%$ with increase in current density from 0.8 to $6.4 \mathrm{Adm}^{-2}$.

\subsection{Surface Morphology and Structure of $\mathrm{Ni}-\mathrm{ZrO}_{2}$ Composite}

The amount of $\mathrm{ZrO}_{2}$ incorporated in the $\mathrm{Ni}-\mathrm{ZrO}_{2}$ nanocomposite electroforms was seen to be about $2 \mathrm{wt} \%$ by EDX analysis. Wang et al have reported $2.70 \mathrm{wt} \%$ of nano $\mathrm{ZrO}_{2}$ (10-30nm) incorporation in Ni matrix obtained by electrodeposition from a Watt's bath. ${ }^{21}$ Simunkova et al have reported higher $(9 \mathrm{wt} \%)$ incorporation of $200 \mathrm{~nm}$ size $\mathrm{ZrO}_{2}$ particles in Ni matrix compared to $40 \mathrm{~nm}$ size particles (3wt\%). ${ }^{8}$ Thus, other researchers have also obtained similar amount of nano $\mathrm{ZrO}_{2}$ particle incorporation in Ni matrix. The mechanism of $\mathrm{ZrO}_{2}$ incorporation has been reported by Wang, Benea et al. ${ }^{21,18}$

The SEM micrograph depicting the surface morphology of the composite electroforms is shown in Figure 3 . It is seen from Figure3a that agglomerates of nano $\mathrm{ZrO}_{2}$ particles are distributed on the surface of pyramidal shaped Ni crystallites. A similar morphology of $\mathrm{ZrO}_{2}$ agglomerates non-uniformly distributed throughout the Ni matrix has been reported by Hou et al. ${ }^{20}$
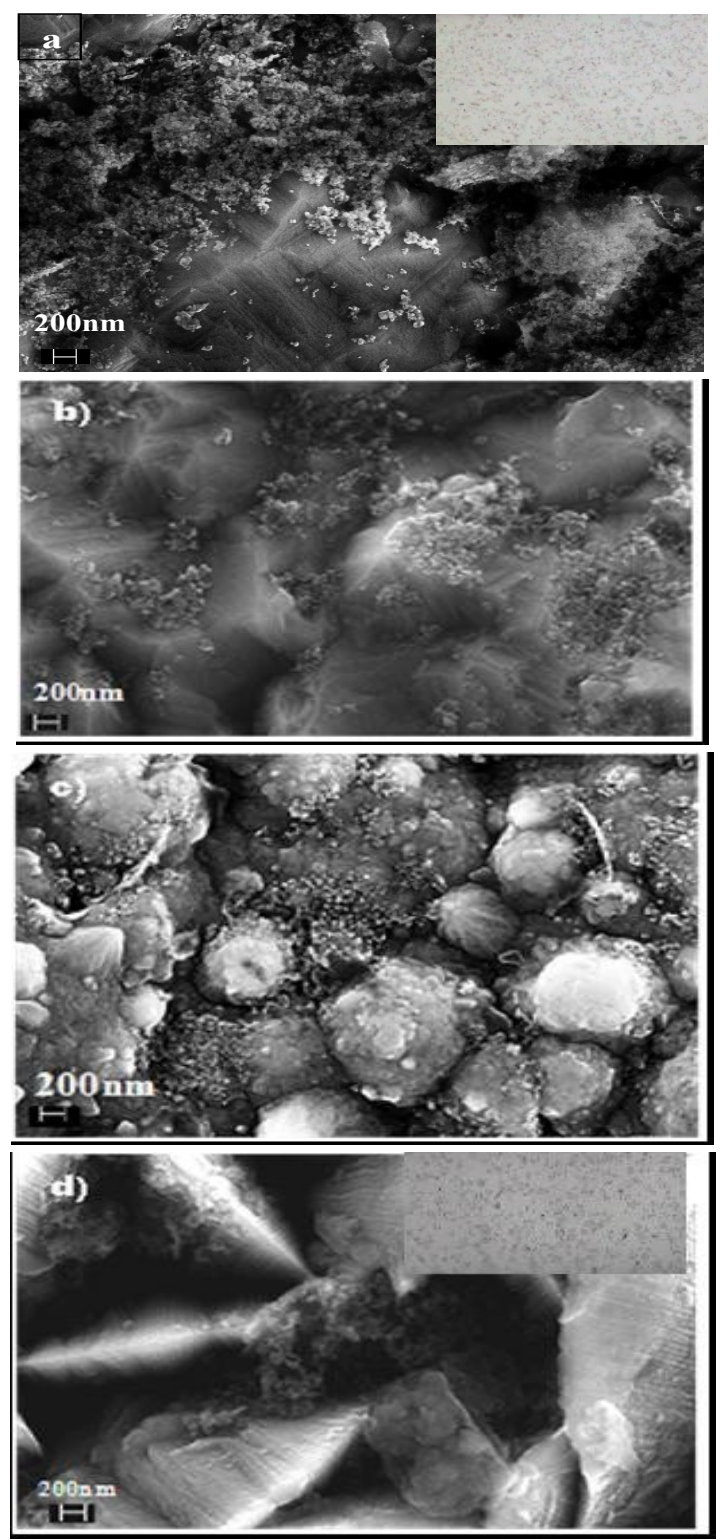

Figure 3. Surface morphology of (a) $\mathrm{Ni}-\mathrm{ZrO}_{2}$ composite coating; Insert shows the cross-sectional optical micrograph (b) $\mathrm{Ni}-10 \mathrm{Co}-\mathrm{ZrO}_{2}$, (c) $\mathrm{Ni}-28 \mathrm{Co}-\mathrm{ZrO}_{2}$ and (d) $\mathrm{Ni}-80-\mathrm{ZrO}_{2}$ composite coatings; Insert shows the cross-sectional optical micrograph 
However, Wang et al have reported a nodular, smooth morphology for high-speed jet electroplated $\mathrm{Ni}-\mathrm{ZrO}_{2}$ coating. ${ }^{29}$ The X-ray diffractogram of the $\mathrm{Ni}-\mathrm{ZrO}_{2}$ nano- composites is shown in Figure 4. The coating was found to exhibit a predominant (200) reflection, accompanied with (111). Reddy et al have observed (111) reflection as the predominant peak for pulse electrodeposited $\mathrm{Ni}^{-} \mathrm{ZrO}_{2}$ composite coatings. ${ }^{23}$ The difference in the current waveforms employed may be the cause for the difference in the predominant reflections. The crystal structure is seen to be fcc. Reflections corresponding to $\mathrm{ZrO}_{2}$ are not observed due to the reduced amount ( $2 \mathrm{wt} \%$ ) of incorporation.

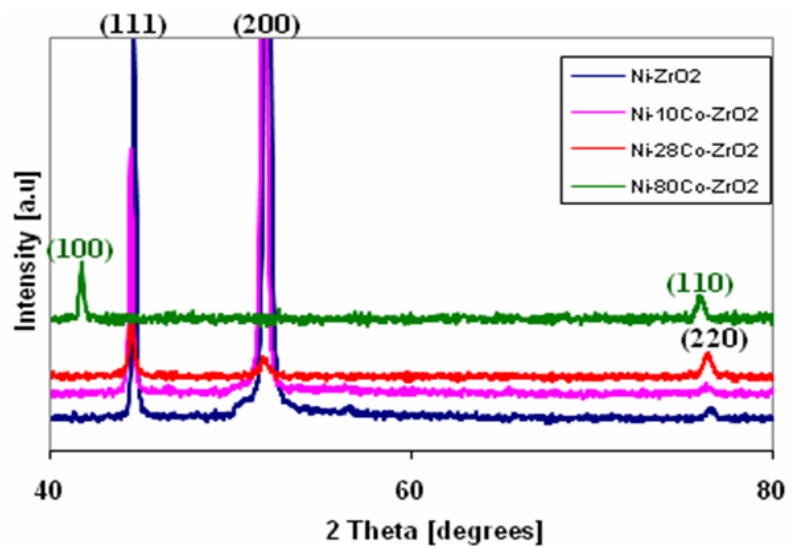

Figure 4. $\mathrm{X}$ - ray diffractogram of (a) $\mathrm{Ni}-\mathrm{ZrO}_{2}$, (b) Ni-10Co- $\mathrm{ZrO}_{2}$, (c) $\mathrm{Ni}-28 \mathrm{Co}-\mathrm{ZrO}_{2}$ and (c) $\mathrm{Ni}-80-\mathrm{ZrO}_{2}$ composite coatings

\subsection{Ni-Co-ZrO $\mathrm{C}_{2}$ Co-Deposition}

Nano $\mathrm{ZrO}_{2}$ particles were incorporated in various $\mathrm{Ni}-\mathrm{Co}$ alloy matrices. The amount of Co incorporated in the composite coatings was in the range of $10-80 \mathrm{wt} \%$. The amount of $\mathrm{ZrO}_{2}$ incorporated in the coatings remained a constant at $2 \mathrm{wt} \%$ for Co content of $10-28 \mathrm{wt} \%$. For a Co content of $80 \mathrm{wt} \%$ the amount of $\mathrm{ZrO}_{2}$ particles incorporated increased to $5 \mathrm{wt} \%$. Thus, an increase in Co content in the coating has resulted in an increase in $\mathrm{ZrO}_{2}$ incorporation. This shows that cobalt has better wettability for the particles compared to Ni. Similar observation has been made by the authors for other inert particles like $\mathrm{SiC}, \mathrm{Si}_{3} \mathrm{~N}_{4} .{ }^{27,2}$ A comparison in the microhardness of Ni-Co alloys and $\mathrm{Ni}-\mathrm{Co}-\mathrm{ZrO}_{2}$ composite coatings is depicted in Figure5.

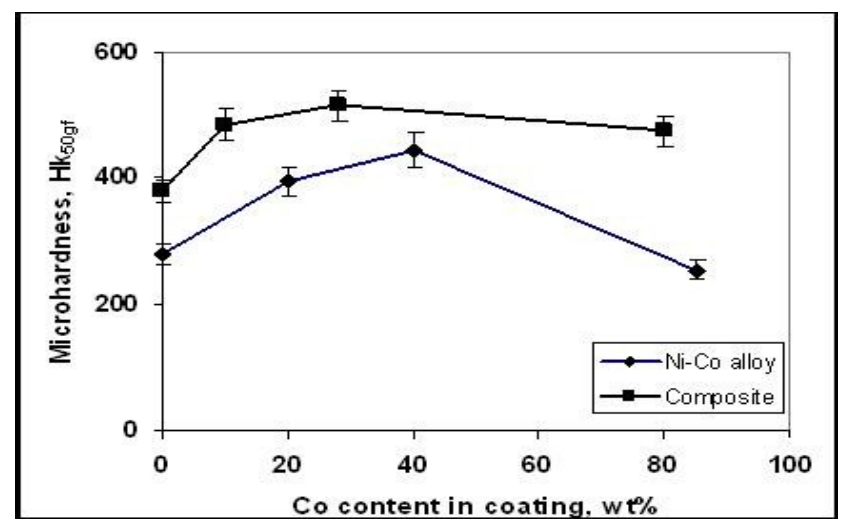

Figure 5. Variation in Microhardness with change in cobalt content in the coating
It is seen from the figure that the microhardness of $\mathrm{Ni}-\mathrm{Co}$ alloys increases with increase in Co content and attains a maxima followed by a decrease in hardness with increase in Co content. The maximum is observed for a Co content of $40 \mathrm{wt} \%$. The decrease in microhardness with increase in Co content is associated with the formation of hep phase. The incorporation of nano $\mathrm{ZrO}_{2}$ particles has increased the microhardness of all the Ni-Co alloys. It is also seen that for a constant Co content in the electrolyte in the presence of $\mathrm{ZrO}_{2}$ particles, a reduction in the Co co-deposition has occurred. This shows that the Co incorporation depends on the nature of the particle co-deposited along with it apart from other deposition conditions. A similar observation has been made by the authors during $\mathrm{Si}_{3} \mathrm{~N}_{4}$ incorporation in Ni-Co matrix. ${ }^{30}$ This aspect needs to be explored further.

A significant increase in the microhardness of the composites is seen in comparison with that of the plain Ni-Co alloys. The microhardness of the composite increased from $380 \mathrm{Hk}$ to a maximum of $515 \mathrm{Hk}$ followed by a marginal drop to $475 \mathrm{Hk}$ (Figure5). The maximum is observed for a $\mathrm{Co}$ content of $28 \mathrm{wt} \%$ in the composite, unlike $40 \mathrm{wt} \%$ in the alloy. An increase in Co content to $80 \mathrm{wt} \%$ resulted in a marginal reduction to $475 \mathrm{Hk}$. It is seen that $\mathrm{ZrO}_{2}$ incorporation has significantly improved the microhardness of Co rich $\mathrm{Ni}-\mathrm{Co}$ alloys. The trend of microhardness reaching a maxima followed by a drop with increase in Co content is similar to that displayed by Ni-Co alloys. ${ }^{30}$ This behaviour has been associated with the change in the crystal structure from fcc to hep with increase in Co content. ${ }^{27}$ The trend in microhardness can also be related to the change in crystallite size. The variation in crystallite size follows the trend of $\mathrm{Ni}-\mathrm{ZrO}_{2}$ $(38 \mathrm{~nm})>\mathrm{Ni}-10 \mathrm{Co}-\mathrm{ZrO}_{2}(36 \mathrm{~nm})>\mathrm{Ni}-28 \mathrm{Co}-\mathrm{ZrO}{ }_{2}(15 \mathrm{~nm})<$ $\mathrm{Ni}-80 \mathrm{Co}-\mathrm{ZrO}_{2}(17 \mathrm{~nm})$. Thus, it is seen that the high microhardness of $\mathrm{Ni}-28 \mathrm{Co}-\mathrm{ZrO}_{2}$ composite can be related with its small crystallite size of $15 \mathrm{~nm}$ which is in accordance with the Hall-Petch relation.

The surface morphology of the Ni-Co- $\mathrm{ZrO}_{2}$ nano- composites is shown in Figure 3. It is seen from Figs.3a and $3 b$ that surface morphology of Ni- $2 \mathrm{ZrO}_{2}$ and $\mathrm{Ni}-10 \mathrm{Co}-2 \mathrm{ZrO}_{2}$ composite coatings are similar i.e. the introduction of $10 \mathrm{wt} \%$ Co has not altered the morphology of Ni matrix. However, in the presence of $28 \mathrm{wt} \%$ Co in the matrix, a transformation from distinct pyramidal crystallite morphology to irregular nodular is seen in Figure3c. Irregular pyramidal matrix morphology was seen for Ni-20Co alloy. ${ }^{29}$ This difference in the matrix morphology is caused by $\mathrm{ZrO}_{2}$ incorporation. An increase in Co content to $80 \mathrm{wt} \%$, the matrix morphology transformed to a ridged structure (Figure3d). A similar morphology has also been exhibited by Ni-80Co alloy. Thus, it is seen that for higher Co contents and very low Ni contents, the $\mathrm{ZrO}_{2}$ incorporation has no influence on the matrix morphology. The changes in the surface morphology for higher Co content are due to the change in the crystal structure from fcc to hcp. A similar change has been observed by the authors for Ni-Co alloys and their other composites. ${ }^{27,2}$ The X-ray diffractogram of $\mathrm{Ni}-\mathrm{Co}-\mathrm{ZrO}_{2}$ nano-composite coatings is shown in Figure 4. It is seen from the figure that upto $10 \mathrm{wt} \% \mathrm{Co}$ content in the coatings, the predominant 
reflection is (200) accompanied with a weak (111) reflection. Similar diffractrogram has been exhibited by plain Ni coating.

The Ni-28Co- $2 \mathrm{ZrO}_{2}$ nano-composite exhibited a predominant (111) orientation accompanied with (200) and (220) reflections. The Ni-20Co alloy was seen to exhibit predominant (200) reflection. This change in the reflections may be the cause for the difference in the morphology between the alloy and composite. This change in the preferred orientation from (200) to (111) is also responsible for the higher microhardness of this composite compared to $\mathrm{Ni}-10 \mathrm{Co}-2 \mathrm{ZrO}_{2}$. All the Ni rich composite coatings exhibited fcc crystal structure and as the $\mathrm{ZrO}_{2}$ incorporation was less, the reflections corresponding to the particles were not seen in the diffractograms. The Co rich Ni-80Co- $5 \mathrm{ZrO}_{2}$ nano-composite exhibited hcp crystal structure with a predominant (100) reflection along with (110). The reflections corresponded to those of hcp Co.

\subsection{Influence of Annealing Treatment on Microhardness}

The influence of annealing temperatures on the microhardness of $\mathrm{Ni}-\mathrm{ZrO}_{2}$ and $\mathrm{Ni}-\mathrm{Co}-\mathrm{ZrO}_{2}$ nano-composites is shown in Figure 6. It is seen from the figure that the trend followed by the $\mathrm{Ni}$ and $\mathrm{Ni}-\mathrm{Co}$ composites is similar to that of plain $\mathrm{Ni}$ and Ni-Co alloy coatings. The microhardness of $\mathrm{Ni}-2 \mathrm{ZrO}_{2}$ nano-composite is stable upto $400^{\circ} \mathrm{C}$ with no significant change in the values. The variation in microhardness of $\mathrm{Ni}-\mathrm{ZrO}{ }_{2}$ coatings with annealing temperature has also been studied by Reddy et al. ${ }^{23}$ They have observed an initial rise in the values upto $200^{\circ} \mathrm{C}$ followed by a drastic reduction at $300^{\circ} \mathrm{C}$ and subsequently a slow but continuous decrease at $600^{\circ} \mathrm{C}$. The cause for the difference in behaviour between Reddy's and present study is, the composite studied by former is pulsed co-deposited and the $\mathrm{ZrO}_{2}$ particles have tetragonal crystal structure ${ }^{23}$ while, the deposition in the present study is direct current deposition and the particles have monoclinic structure. The microhardness of Ni-10Co$2 \mathrm{ZrO}_{2}$ composites is higher than that of $\mathrm{Ni}-2 \mathrm{ZrO}_{2}$ composite.

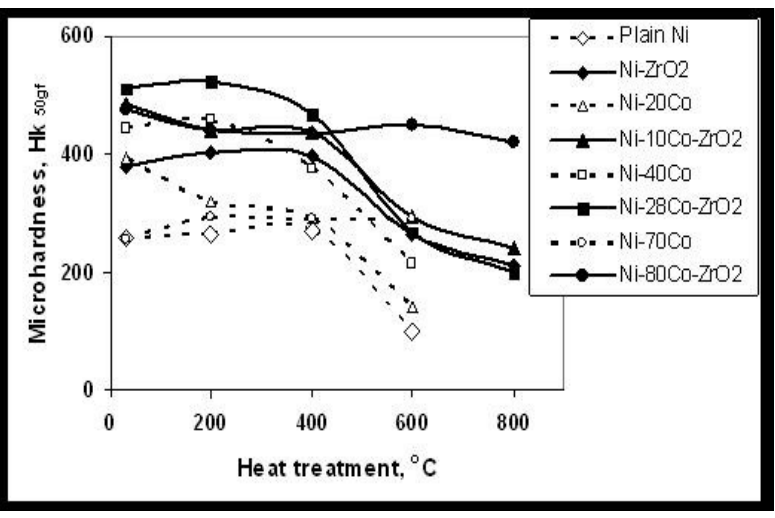

Figure 6. Influence of temperature on the microhardness of $\mathrm{Ni}-\mathrm{ZrO}_{2}$ and $\mathrm{Ni}-\mathrm{Co}-\mathrm{ZrO}_{2}$ composite coatings

A $9 \%$ reduction in microhardness is seen at a temperature of $400^{\circ} \mathrm{C}$ compared to ambient temperature microhardness. This trend has been observed for all the Ni-Co- $\mathrm{ZrO}_{2}$ nano- composites, irrespective of the Co content in the matrix. At temperatures of $600^{\circ} \mathrm{C}, \mathrm{Ni}-\mathrm{ZrO}_{2}$ coating exhibited a reduction in microhardness of about $30 \%$ (relative to ambient condition). While, Ni-Co- $\mathrm{ZrO}_{2}$ nano-composites exhibited a reduction of $37 \%$ and $47 \%$ for a Co content of $10 \mathrm{wt} \%$ and $28 \mathrm{wt} \%$ in the matrix respectively. Only a $5 \%$ reduction in microhardness is observed at $600^{\circ} \mathrm{C}$ for $\mathrm{Ni}-80 \mathrm{Co}-5 \mathrm{ZrO}_{2}$ composite coating. This shows that this nano-composite possesses better stability in terms of microhardness compared to the other Ni-Co- $\mathrm{ZrO}_{2}$ and $\mathrm{Ni}-\mathrm{ZrO}_{2}$ composites. A further increase in the annealing temperature has resulted in above $50 \%$ decrease in the microhardness for $\mathrm{Ni}-2 \mathrm{ZrO}_{2}$, $\mathrm{Ni}-10 \mathrm{Co}-2 \mathrm{ZrO}_{2}$ and $\mathrm{Ni}-28 \mathrm{Co}-2 \mathrm{ZrO}_{2}$ nano-composites. This confirms that the microhardness of $\mathrm{Ni}$ rich $\mathrm{ZrO}_{2}$ composites is less stable at temperatures beyond $600^{\circ} \mathrm{C}$. The Ni-80Co$5 \mathrm{ZrO}_{2}$ nano-composite displays only an $11 \%$ reduction in the values even at temperatures of $800^{\circ} \mathrm{C}$ thereby showing its better stability compared to all the other three coatings studied.

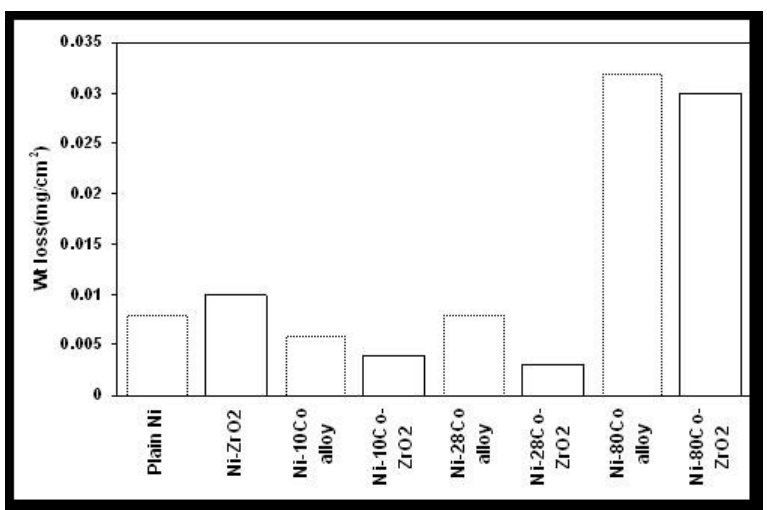

Figure 7. Comparative weight loss of $\mathrm{Ni}-\mathrm{ZrO}_{2}$ and $\mathrm{Ni}-\mathrm{Co}-\mathrm{ZrO}_{2}$ composites after immersion in $3.5 \% \mathrm{NaCl}$ for 168 hours

\subsection{Corrosion Behaviour}

\subsubsection{Immersion Corrosion}

The corrosion rate expressed in terms of weight loss on immersion in $3.5 \% \mathrm{NaCl}$ is shown in Figure 7 . It is seen from the figure that the weight loss of coating on immersion in $\mathrm{NaCl}$ is marginally less for the $\mathrm{ZrO}_{2}$ incorporated $\mathrm{Ni}-\mathrm{Co}$ composites compared to $\mathrm{Ni}-\mathrm{Co}$ alloy coatings. In other words, the corrosion resistance of the composite coatings is better, although to a smaller extent, compared to the plain coatings. It is also seen that the weight loss of Ni-28Co$\mathrm{ZrO}_{2}$ composite is less compared to $\mathrm{Ni}-\mathrm{ZrO}_{2}$ and other $\mathrm{Ni}-\mathrm{Co}-\mathrm{ZrO}_{2}$ composite coatings. Thus, it can be concluded that the corrosion resistance of Ni-Co alloy and the composite possessing Co content close to $25 \pm 5 \mathrm{wt} \%$ is better compared to plain $\mathrm{Ni}$, its composite and other Ni-Co alloys, their composites. Similar observation for the Ni-Co alloys has been observed by the authors in earlier studies using Potentiodynamic polarization and Impedance analysis. ${ }^{30}$ Another conclusion that can be drawn from the figure is that an increase in weight loss is seen with increase in Co content in the coatings. Thus, revealing that $\mathrm{Co}$ rich $\mathrm{Ni}-\mathrm{Co}$ 
coatings have poor corrosion resistance.

The composite coatings exposed to the corrosive medium of $3.5 \% \mathrm{NaCl}$ were subjected to FESEM analysis to study the surface morphology, and EDX analysis to identify the compositional changes. The surface morphology of the coatings after immersion in the corrosive medium are displayed in Figure 8 and the elemental composition is shown in Table 3. Ni- $\mathrm{ZrO}_{2}$ coating after immersion in the corrosive medium shows the presence of deep depressions (Figure 8a). The EDX analysis revealed that the zirconia content within the depression is less compared to that in the matrix (Table $3)$.

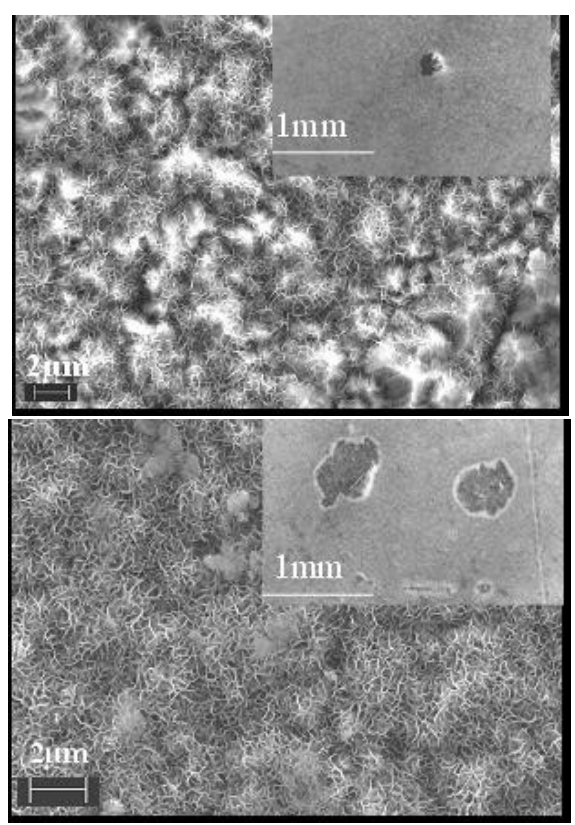

Figure 8. Surface morphology of corroded surface of (a) $\mathrm{Ni}_{\mathrm{ZrO}}$, (b) $\mathrm{Ni}-10 \mathrm{Co}-\mathrm{ZrO}_{2}$ composite coatings; Inset shows the image at low magnification

This confirms the occurrence of dislodgement of $\mathrm{ZrO}_{2}$ particles. A change in the matrix morphology is also seen.

Table 3. Elemental composition analysis of $\mathrm{Ni}-\mathrm{ZrO}_{2}$ and $\mathrm{Ni}-\mathrm{Co}-\mathrm{ZrO}_{2}$ composite coatings prior to and after immersion in corrosive medium, $3.5 \%$ $\mathrm{NaCl}$

\begin{tabular}{|c|c|c|c|c|}
\hline & $\mathrm{Ni}-\mathrm{ZrO}_{2}$ & $\mathrm{Ni}-10 \mathrm{Co}-\mathrm{ZrO}_{2}$ & $\mathrm{Ni}-28 \mathrm{Co}-\mathrm{ZrO}_{2}$ & $\begin{array}{c}\mathrm{Ni}-80 \mathrm{Co}- \\
\mathrm{ZrO}_{2}\end{array}$ \\
\hline $\begin{array}{l}\text { Ni wt } \% \\
\text { Before }\end{array}$ & Bal & $\mathrm{Bal}$ & Bal & Bal \\
\hline After & $\mathrm{Bal}$ & $\mathrm{Bal}$ & $\mathrm{Bal}$ & $\mathrm{Bal}$ \\
\hline $\begin{array}{l}\text { Co wt } \% \\
\text { Before }\end{array}$ & - & 10 & 28 & 80 \\
\hline After & - & $9 \mathrm{~m}, 7 \mathrm{p}$ & $30 \mathrm{~m}, 29 \mathrm{p}$ & 64 \\
\hline $\begin{array}{l}\mathrm{Zrwt} \% \\
\text { Before }\end{array}$ & 2 & 2 & 2 & 5 \\
\hline After & $3 \mathrm{~m}, 1 \mathrm{p}$ & $4 m, 2 p$ & $1.45 \mathrm{~m}, 1.69 \mathrm{p}$ & 5.6 \\
\hline $\begin{array}{l}\mathrm{Cl} \text { wt } \% \\
\text { Before }\end{array}$ & - & - & - & - \\
\hline After & $\begin{array}{c}0.41 \mathrm{~m}, \\
15.0 \mathrm{p}\end{array}$ & $0.8 \mathrm{~m}, 14.0 \mathrm{p}$ & $0.3 \mathrm{~m}, 5.0 \mathrm{p}$ & 1.0 \\
\hline $\begin{array}{l}\text { O wt } \% \\
\text { Before }\end{array}$ & - & - & - & - \\
\hline After & $13 \mathrm{~m}, 29 \mathrm{p}$ & $23 \mathrm{~m}, 28 \mathrm{p}$ & $12 \mathrm{~m}, 15 \mathrm{p}$ & 21 \\
\hline
\end{tabular}

$\mathrm{p}$ - depression, m-matrix, Bal-Balance
Depressions are seen in the case of $\mathrm{Ni}-10 \mathrm{Co}-\mathrm{ZrO}_{2}$ composite coating also as shown in Figure 8b. It is seen from EDX analysis that the zirconia and cobalt content within the depression are less compared to the matrix. This also confirms the removal of the particles. Also, the chlorine and oxygen contents are higher within the depression (Figure 8c) compared to the matrix. The surface morphology of $\mathrm{Ni}-28 \mathrm{Co}-\mathrm{ZrO}_{2}$ composite coating is shown in Figure 8d. It is seen from the figure that very shallow depressions are formed along with a nodular matrix. No appreciable change in the surface morphology is seen after immersion. The EDX analysis illustrates no appreciable change in the zirconia content. Also, the change in the concentration of chlorine and oxygen contents are seen to be less in the shallow depressions compared to those observed in $\mathrm{Ni}-10 \mathrm{Co}-\mathrm{ZrO}_{2}$ and $\mathrm{Ni}-\mathrm{ZrO}_{2}$ coatings. This shows that the corrosion resistance of $\mathrm{Ni}-28 \mathrm{Co}-\mathrm{ZrO}_{2}$ composite is better compared to the other coatings. This is in correlation with the low weight loss of this coating compared to the other coatings studied. The surface morphology of $\mathrm{Ni}-80 \mathrm{Co}-\mathrm{ZrO}_{2}$ composite coating is shown in Figure 8e. No depression is seen but the surface appears to be loosely packed branched thin filaments, causing the penetration of the corrosion-active species within the coating. The EDX analysis revealed a drastic reduction in Co content from $80 \mathrm{wt} \%$ to $64 \mathrm{wt} \%$ thus, confirming the dissolution of the matrix (Table 3).

Thus, the increased corrosion rate of the Co rich Ni-Co$\mathrm{ZrO}_{2}$ composite can be attributed to the dissolution of the matrix.
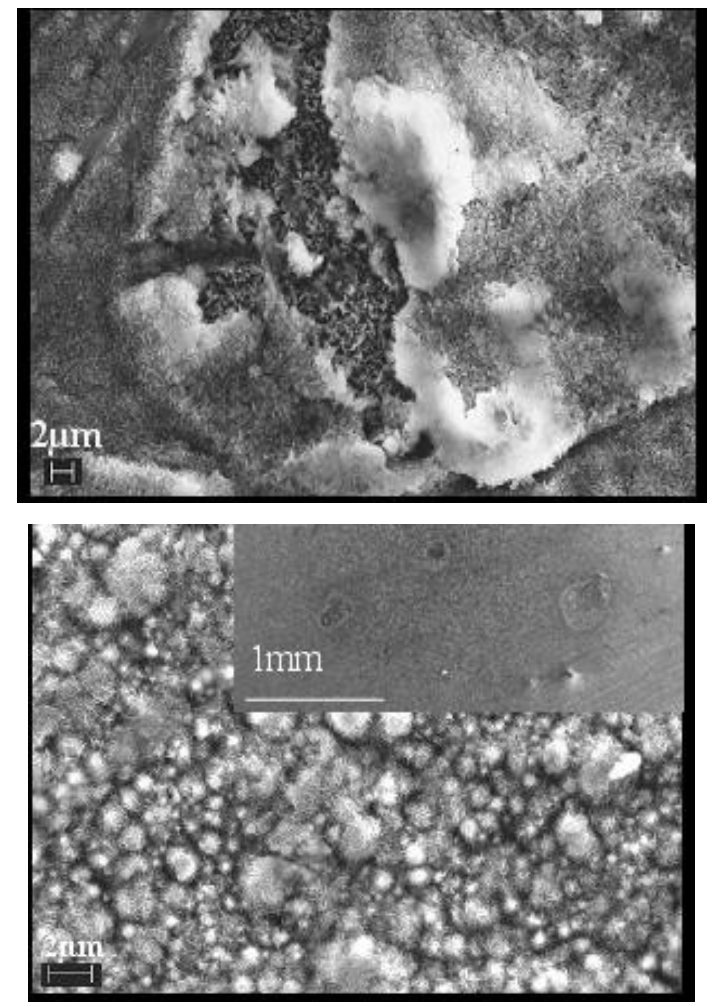

Figure 8. Surface morphology of corroded surface of (a) $\mathrm{Ni}^{-} \mathrm{ZrO}_{2}$, (b) $\mathrm{Ni}-10 \mathrm{Co}-\mathrm{ZrO}_{2}$, (c) higher magnification image of Ni-10Co $\mathrm{ZrO}_{2}$ composite, (d) $\mathrm{Ni}-28 \mathrm{Co}-\mathrm{ZrO}_{2}$ and (e) $\mathrm{Ni}-80-\mathrm{ZrO}_{2}$ composite coatings; Inset shows the image at low magnification 


\subsubsection{Polarization Studies}

The corrosion behaviour of the coatings was analyzed by Polarization studies and the polarization curves are displayed in Figure 9.

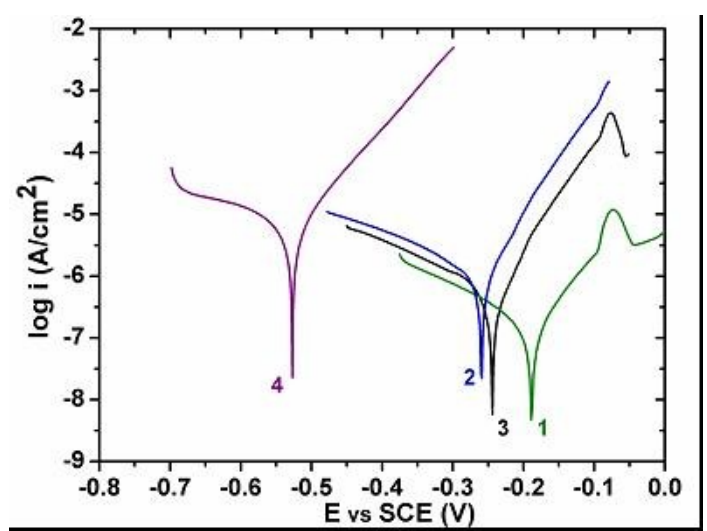

Figure 9. Polarization curves of $\mathrm{Ni}-\mathrm{ZrO}_{2}(1), \mathrm{Ni}-10 \mathrm{Co}-\mathrm{ZrO}_{2}(2), \mathrm{Ni}-28 \mathrm{Co}-$ $\mathrm{ZrO}_{2}$ (3) and $\mathrm{Ni}-80 \mathrm{Co}-\mathrm{ZrO}_{2}$ (4) composites

The electrochemical parameters - corrosion current density $\mathrm{i}_{\text {corr }}$ and corrosion potential $\mathrm{E}_{\text {corr }}$ obtained from Potentiodynamic polarization studies are listed in Table 4.

Table 4. Corrosion parameters obtained from Polarization studies

\begin{tabular}{|ccc|}
\hline Coating & $\mathrm{E}_{\text {corr }}, \mathrm{V}$ & $\mathrm{I}_{\text {corr }}, \mu \mathrm{A} / \mathrm{cm}^{2}$ \\
\hline $\mathrm{Ni}-\mathrm{ZrO}{ }_{2}$ & -0.189 & 0.170 \\
\hline $\mathrm{Ni}-10 \mathrm{Co}-\mathrm{ZrO}_{2}$ & -0.259 & 0.853 \\
\hline $\mathrm{Ni}-28 \mathrm{Co}-\mathrm{ZrO}_{2}$ & -0.244 & 0.574 \\
\hline $\mathrm{Ni}-80 \mathrm{Co}-\mathrm{ZrO}_{2}$ & -0.527 & 7.325 \\
\hline
\end{tabular}

The corrosion current $\mathrm{i}_{\text {corr }}$ for plain $\mathrm{Ni}$ is found to be $1.060 \mu \mathrm{A} / \mathrm{cm}^{2}$. The incorporation of $\mathrm{ZrO}_{2}$ in $\mathrm{Ni}$ matrix reduced the corrosion current to $0.170 \mu \mathrm{A} / \mathrm{cm}^{2}$. This indicates that the addition of $\mathrm{ZrO}_{2}$ in Ni matrix has improved its corrosion resistance. The reinforcement of $\mathrm{ZrO}_{2}$ in Ni-Co matrices follows the trend $\mathrm{Ni}-28 \mathrm{Co}-\mathrm{ZrO}_{2}\left(0.574 \mu \mathrm{A} / \mathrm{cm}^{2}\right)<$ $\mathrm{Ni}-10 \mathrm{Co}-\mathrm{ZrO}_{2}\left(0.853 \mu \mathrm{A} / \mathrm{cm}^{2}\right)<\mathrm{Ni}-80 \mathrm{Co}-\mathrm{ZrO}_{2}\left(7.325 \mu \mathrm{A} / \mathrm{cm}^{2}\right.$ ). It is seen that the least corrosion current value i.e in other words better corrosion resistance is displayed by $\mathrm{Ni}-28 \mathrm{Co}-\mathrm{ZrO}_{2}$ coating compared to the other $\mathrm{Ni}-\mathrm{Co}-\mathrm{ZrO}_{2}$ composites. The corrosion potential $\mathrm{E}_{\text {corr }}$ of plain $\mathrm{Ni}$ is found to be $-0.326 \mathrm{~V}$, the incorporation of $\mathrm{ZrO}_{2}$ in $\mathrm{Ni}$ matrix resulted in a positive shift in potential to $-0.189 \mathrm{~V}$. This indicates that the addition of $\mathrm{ZrO}_{2}$ in $\mathrm{Ni}$ matrix has improved the corrosion resistance. It is also seen from the table that no significant change in the $\mathrm{E}_{\text {corr }}$ values is seen between $\mathrm{Ni}-10 \mathrm{Co}-\mathrm{ZrO}_{2} \quad(-0.259 \mathrm{~V})$ and $\mathrm{Ni}-28 \mathrm{Co}-\mathrm{ZrO}_{2} \quad(-0.244 \mathrm{~V})$ however, the values are less positive compared to $\mathrm{Ni}-\mathrm{ZrO}_{2}$ coating. This conveys that the corrosion resistance of $\mathrm{Ni}-\mathrm{ZrO}_{2}$ composite is better compared to Ni-Co-ZrO 2 composites. An increase in Co content in the matrix to $80 \mathrm{wt} \%$ resulted in a significant shift to more negative value $(-0.527 \mathrm{~V})$ indicating its poor corrosion behaviour compared to all the coatings studied. Thus, it is understood that addition of cobalt beyond $28 \mathrm{wt} \%$ impairs the beneficial corrosion effect of $\mathrm{Ni}$.

\subsubsection{Electrochemical Impedance Studies}

The impedance plots of $\mathrm{Ni}-\mathrm{ZrO}_{2}$ and $\mathrm{Ni}-\mathrm{Co}-\mathrm{ZrO}_{2}$ composites with various cobalt contents are shown in Figures 10 and 11. Figure 10 represents the Nyquist plot. The interception of $Z^{\prime}$ in the Nyquist plot at higher frequencies is ascribed as electrolytic bulk resistance $R_{s}$ and at lower frequencies the interception is ascribed as the charge transfer resistance $R_{c t}$.

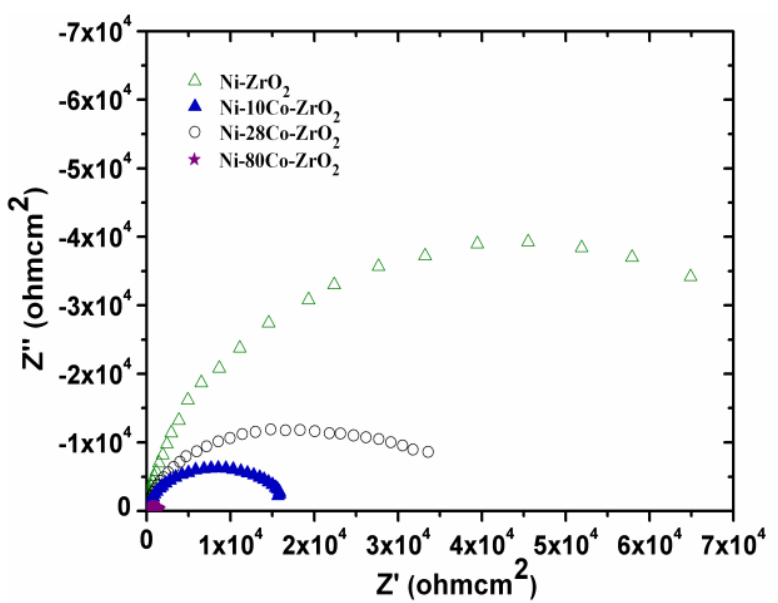

Figure 10. Nyquist plots of $\mathrm{Ni}-\mathrm{ZrO}{ }_{2}, \mathrm{Ni}-10 \mathrm{Co}-\mathrm{ZrO}{ }_{2}, \mathrm{Ni}-28 \mathrm{Co}-\mathrm{ZrO}_{2}$ and $\mathrm{Ni}-80 \mathrm{Co}-\mathrm{ZrO}_{2}$ composites

The Nyquist plot shows single semicircle for $\mathrm{Ni}-\mathrm{ZrO}_{2}$ and $\mathrm{Ni}-\mathrm{Co}-\mathrm{ZrO}_{2}$ composite coatings and this can be associated with single time constant i.e. the charge transfer process in the coating/electrolyte interface. Bode plot of frequency vs phase angle (Fig.11) displayed a single, broad peak indicating the large capacitive behaviour of the coatings. The single peak corresponded to the coating electrolyte $(3.5 \% \mathrm{NaCl})$ interface.

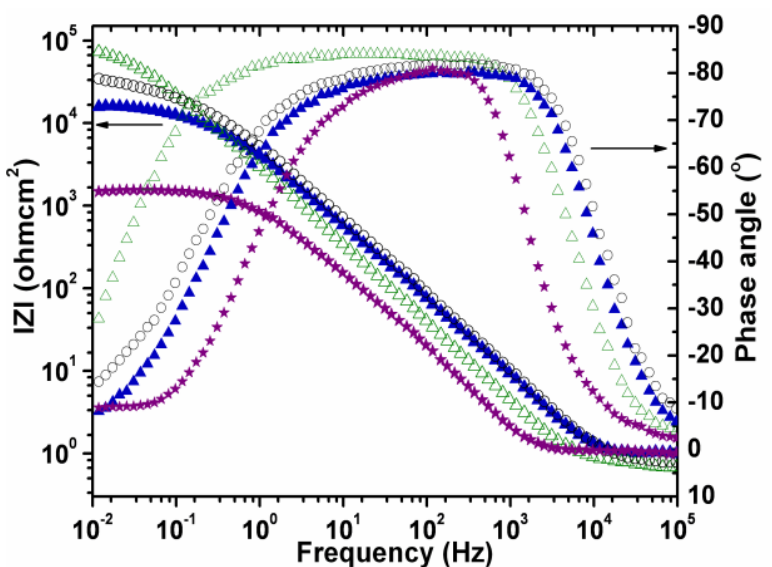

Figure 11. Bode Plots of $\mathrm{Ni}-\mathrm{ZrO}{ }_{2}, \mathrm{Ni}-10 \mathrm{Co}-\mathrm{ZrO}_{2}, \mathrm{Ni}-28 \mathrm{Co}-\mathrm{ZrO}_{2}$ and $\mathrm{Ni}-80 \mathrm{Co}-\mathrm{ZrO}{ }_{2}$ composites

This behaviour can be modeled as a parallel combination of a double layer capacitance $\mathrm{C}_{\mathrm{dl}}$ and a charge transfer resistance $R_{c t}$ both of which are in series with the solution resistance $R_{s}$ between the working electrode WE and the tip of the Luggin capillary. The simple Randles circuit described as $\mathrm{R}(\mathrm{QR})$ was used for fitting the plots obtained for the 
coatings studied and the fitted values are displayed in Table 5. The double layer capacitance provides information about the polarity and the amount of charge at the coating electrolyte interface.

Table 5. Electrochemical parameters obtained from Impedance studies of $\mathrm{Ni}-\mathrm{ZrO}_{2}$ and $\mathrm{Ni}-\mathrm{Co}-\mathrm{ZrO}_{2}$ composites

\begin{tabular}{|l|l|l|l|l|}
\hline Coating & $\mathrm{Rs}, \Omega \mathrm{cm}^{2}$ & $\mathrm{Q}_{\mathrm{dl}}, \mu \mathrm{Ss}^{\mathrm{n}} \mathrm{cm}^{-2}$ & $\mathrm{n}$ & $\mathrm{R}_{\mathrm{ct}}, \mathrm{k} \Omega \mathrm{cm}^{2}$ \\
\hline $\mathrm{Ni}-\mathrm{ZrO}{ }_{2}$ & 0.90 & 31.6 & 0.94 & 83.87 \\
\hline $\mathrm{Ni}-10 \mathrm{Co}-\mathrm{ZrO}_{2}$ & 0.91 & 42.8 & 0.90 & 15.91 \\
\hline $\mathrm{Ni}-28 \mathrm{Co}-\mathrm{ZrO}_{2}$ & 0.89 & 34.6 & 0.93 & 32.90 \\
\hline $\mathrm{Ni}-80 \mathrm{Co}-\mathrm{ZrO}_{2}$ & 1.10 & 79.7 & 0.89 & 1.534 \\
\hline
\end{tabular}

The $\mathrm{R}_{\mathrm{ct}}$ values obtained increased in the order: $\mathrm{Ni}-\mathrm{ZrO}_{2}$, $\mathrm{Ni}-28 \mathrm{Co}-\mathrm{ZrO}_{2}, \mathrm{Ni}-10 \mathrm{Co}-\mathrm{ZrO}_{2}$ and Ni-80Co-ZrO${ }_{2}$. The Rct value being the highest for $\mathrm{Ni}-\mathrm{ZrO} 2$ coating indicates that the active area available for corrosive attack is less or alternatively the corrosion resistance is better compared to the others. The capacitance $\mathrm{C}$ is represented by a general diffusion related element $\mathrm{Q}$ which is defined as a constant phase element. This accounts for the deviation from the ideal dielectric behaviour and is related to surface inhomogenity. This element is mathematically written in the admittance form as $\mathrm{Y}^{*}(\omega)=\mathrm{Y}_{\mathrm{o}}(\mathrm{j} \omega)^{\mathrm{n}}$ where, $\mathrm{Y}_{\mathrm{o}}$ is an adjustable parameter used in the non-linear least square fitting and $n$ is an adjustable parameter in the range of 0.5 to 1 . The value of $n$ is obtained from the slope of frequency vs $|\mathrm{Z}|$ plot (Fig.11). The phase angle $\theta$ can vary between $90^{\circ}$ (for a perfect capacitor $n=1$ ) to $0^{\circ}$ (for a perfect resistor $n=0$ ). It is understood from Table 5 that $\mathrm{Q}_{\mathrm{dl}}$ value is very low for $\mathrm{Ni}-\mathrm{ZrO}_{2}$ compared to $\mathrm{Ni}-\mathrm{Co}-\mathrm{ZrO}_{2}$. Among the Ni-Co- $\mathrm{ZrO}_{2}$ composites, $\mathrm{Ni}-28 \mathrm{Co}-\mathrm{ZrO}_{2}$ composites display lower values and close to $\mathrm{Ni}-\mathrm{ZrO}_{2}$ compared to $\mathrm{Ni}-10 \mathrm{Co}-\mathrm{ZrO}_{2}$ and $\mathrm{Ni}-80 \mathrm{Co}-\mathrm{ZrO}_{2}$ composites. This indicates that addition of around $28 \mathrm{wt} \%$ of Co improved the surface morphology of the coating and decreased the surface defects and further increase or decrease in cobalt contents resulted in a reverse effect. Further, the $\mathrm{n}_{\mathrm{dl}}$ values are 0.93 and 0.94 for $\mathrm{Ni}-28 \mathrm{Co}-\mathrm{ZrO}_{2}$ and $\mathrm{Ni}-\mathrm{ZrO}_{2}$ composites respectively indicating low capacitive behaviour of these coatings. Whereas, the values are 0.89 , 0.90 for $\mathrm{Ni}-80 \mathrm{Co}-\mathrm{ZrO}_{2}$ and $\mathrm{Ni}-10 \mathrm{Co}-\mathrm{ZrO}_{2}$ coatings respectively indicating further lower capacitive behaviour of the coatings. Bode plot Fig.11 shows that $\theta$ for $\mathrm{Ni}-\mathrm{ZrO}_{2}$ and $\mathrm{Ni}-28 \mathrm{Co}-\mathrm{ZrO}_{2}$ coatings are almost $85^{\circ}$ whereas it is $80^{\circ}$ for $\mathrm{Ni}-10 \mathrm{Co}-\mathrm{ZrO}_{2}$ and $\mathrm{Ni}-80 \mathrm{Co}-\mathrm{ZrO}_{2}$ coatings. This also shows that the capacitive behaviour of the former coatings is better compared to the latter.

A difference in the corrosion behaviour is seen between the immersion and polarization studies. Ni-28Co- $\mathrm{ZrO}_{2}$ composite is seen to display better immersion corrosion resistance in terms of weight loss while, the Electrochemical studies showed that $\mathrm{Ni}-\mathrm{ZrO}_{2}$ composite displays better corrosion resistance.

\subsection{Wear Behaviour}

The comparative wear volume loss for plain $\mathrm{Ni}, \mathrm{Ni}-\mathrm{Co}$ alloys and $\mathrm{Ni} / \mathrm{Ni}-\mathrm{Co}-\mathrm{ZrO}_{2}$ composite coatings is listed in Table 6. It is seen from the table that the wear volume loss for the composite coatings is remarkably less compared to that of plain $\mathrm{Ni}$ and Ni-Co alloy coatings.

Table 6. Comparative wear volume loss observed in $\mathrm{Ni}-\mathrm{ZrO}_{2}$ and $\mathrm{Ni}-\mathrm{Co}-\mathrm{ZrO}_{2}$ composites

\begin{tabular}{|cc|}
\hline Coating & Wear volume loss $\mathrm{X}^{-4} \mathrm{~mm}^{3} / \mathrm{m}$ \\
\hline Plain Ni & 4.35 \\
\hline $\mathrm{Ni}-28 \mathrm{Co}$ & 0.88 \\
\hline $\mathrm{Ni}-70 \mathrm{Co}$ & 2.54 \\
\hline $\mathrm{Ni}-\mathrm{ZrO}{ }_{2}$ & 1.73 \\
\hline $\mathrm{Ni}-10 \mathrm{Co}-\mathrm{ZrO}_{2}$ & 0.0083 \\
\hline $\mathrm{Ni}-28 \mathrm{Co}-\mathrm{ZrO}_{2}$ & 0.0119 \\
\hline $\mathrm{Ni}-80 \mathrm{Co}-\mathrm{ZrO}_{2}$ & 0.764 \\
\hline
\end{tabular}

The Ni-20Co alloy is seen to display the least material volume loss i.e. better wear resistance. It is also seen that the addition of $\mathrm{Co}$ to $\mathrm{Ni}$ improves the wear resistance irrespective of the Co content added. The volume loss for the $\mathrm{Ni}-\mathrm{Co}-\mathrm{ZrO}_{2}$ composites follows the order: Ni-10Co- $\mathrm{ZrO}_{2}$, $\mathrm{Ni}-28 \mathrm{Co}-\mathrm{ZrO}_{2}<\mathrm{Ni}-80 \mathrm{Co}-\mathrm{ZrO}_{2}<\mathrm{Ni}-\mathrm{ZrO}_{2}$. This may be correlated to their microhardness values. Thus, the wear behaviour is in accordance with the Archard's law wherein the wear resistance is proportional to the microhardness. The material volume loss is seen to increase significantly for $\mathrm{Ni}-80 \mathrm{Co}-5 \mathrm{ZrO}_{2}$ composite similar to that of $\mathrm{Ni}-80 \mathrm{Co}$ alloy. However, the increase is less compared to $\mathrm{Ni}-\mathrm{ZrO}_{2}$ composite. This shows that the addition of $\mathrm{Co}$ to $\mathrm{Ni}$ improves its wear resistance even in the presence of $\mathrm{ZrO}_{2}$ particles.

\section{Conclusions}

The effect of nano $\mathrm{ZrO}_{2}$ incorporation in $\mathrm{Ni}$ and $\mathrm{Ni}-\mathrm{Co}$ matrix was studied by developing $\mathrm{Ni}-\mathrm{ZrO}_{2}$ and $\mathrm{Ni}-\mathrm{Co}-\mathrm{ZrO}_{2}$ composites through electrodeposition method under optimized conditions with respect of microhardness. The FESEM studies showed that the surface morphology of $\mathrm{Ni}-\mathrm{ZrO}_{2}$ composites comprised of polyhedral crystallites along with agglomerated $\mathrm{ZrO}_{2}$ particles. However, the surface morphology of $\mathrm{Ni}-\mathrm{Co}-\mathrm{ZrO}_{2}$ composites depended on the $\mathrm{Co}$ content. A change in morphology from polyhedral- nodular-ridged was observed with increase in Co content from $10 \mathrm{wt} \%$ - 80wt \%. A change in crystal structure from fcc to hcp was seen for a similar change in Co content. It was observed from the thermal stability studies that the stability in terms of microhardness was higher for $\mathrm{Co}$ rich $\mathrm{Ni}-80 \mathrm{Co}-$ $5 \mathrm{ZrO}_{2}$ composite coating upto temperatures of $800^{\circ} \mathrm{C}$ compared to $\mathrm{Ni}-\mathrm{ZrO}_{2}$ and other $\mathrm{Ni}$ rich $\mathrm{Ni}-\mathrm{Co}-\mathrm{ZrO}_{2}$ composite coatings. The immersion corrosion studies revealed that the corrosion occurred by localized pitting in the case of $\mathrm{Ni}$ rich $\mathrm{Ni}-\mathrm{Co} / \mathrm{Ni}$ composites and that the corrosion rate was the least in $\mathrm{Ni}-28 \mathrm{Co}-\mathrm{ZrO}_{2}$ composite coating. Ni-80Co- $5 \mathrm{ZrO}_{2}$ composite displayed uniform and higher corrosion rate compared to Ni rich composites. However, the polarization and electrochemical studies showed that the corrosion behaviour of $\mathrm{Ni}-\mathrm{ZrO}_{2}$ composite was better than that of $\mathrm{Ni}-\mathrm{Co}$ composites. However, the behaviour of $\mathrm{Ni}-28 \mathrm{Co}-\mathrm{ZrO}_{2}$ coating is very 
close to that of $\mathrm{Ni}-\mathrm{ZrO}_{2}$ coating. It was seen from the wear studies that $\mathrm{Ni}-10 \mathrm{Co}-2 \mathrm{ZrO}_{2}, \mathrm{Ni}-28 \mathrm{Co}-2 \mathrm{ZrO}_{2}$ composites displayed better wear resistance. Thus, Ni-28Co- $2 \mathrm{ZrO}_{2}$ composite appears to be optimum in terms of corrosion and wear resistance. Depending on the functional requirement, $\mathrm{Ni}-\mathrm{Co}-\mathrm{ZrO}_{2}$ composite coatings can be tailor made to meet different needs.

\section{ACKNOWLEDGEMENTS}

The authors would like to thank the Director, NAL for permission to carry out this study. A special word of thanks to Mr.Siju, Ms.Latha and Mr.Muniprakash for their assistance in performing the FESEM, microhardness and wear analysis. Ms.Kavitha is also acknowledged for her assistance in performing the experiments.

\section{REFERENCES}

[1] Robertson, A, Erb, U, Palumbo, G, 1999, "Practical applications for electrodeposited nanocrystalline materials." Nanostruct. Mater., 12, 1035-1040

[2] Wang, W, Qian, SQ, Zhou XY, 2010, "Microstructure and Oxidation-resistant of $\mathrm{ZrO}_{2} / \mathrm{Ni}$ coatings applied by highspeed jet electroplating. " J. Mater. Sci., 45, 1617-1621

[3] Gul H, Kihc F, Aslan S, Alp A, Akbulut H, 2009, "Characteristics of electro-co-deposited $\mathrm{Ni}-\mathrm{Al}_{2} \mathrm{O}_{3}$ nano- particle reinforced metal matrix composite (MMC) coatings.” Wear, 267, 976-990

[4] Wang S-C, Wei W-C. J,2003, "Kinetics of electroplating process of nano-sized ceramic particle/Ni composite." Mater. Chem. Phys., 78, 574-580

[5] Carac G, Benea L, Iticescu C, Lampke T, Steinhauser S, Wielage B, 2004, "Codeposition of cerium oxide with nickel and cobalt: Correlation between microstrucutre and microhardness." Surf. Eng., 20, 353-359

[6] Liu Y, Ren L, Yu S, Han Z, 2008, "Influence of current density on nano- $\mathrm{Al}_{2} \mathrm{O}_{3} / \mathrm{Ni}+\mathrm{Co}$ bionic gradient composite coatings by electrodeposition." J. Univ. Sci. Technol., 15, 633-637.

[7] Xiaozhen L, Xin L, Aibing Y, Weijue H, 2009, "Preparation and Tribological performance of electrodeposited $\mathrm{Ni}_{-} \mathrm{TiB}_{2}-$ $\mathrm{Dy}_{2} \mathrm{O}_{3}$ composite coatings.”J. Rare Earth, 27, 480-485

[8] Simunkova H, Garcia P.P, Wosik J, Angerer P, Kronberger H, Nauer G .E, 2009, “ The fundamentals of nano- and submicroscaled ceramic particle incorporation into electrodeposited $\mathrm{Ni}$ layers : Zeta potential measurements." Surf. Coat.Technol., 203, 1806-1814

[9] Balathandan S, Annamalai V.E, Seshadri S.K, 1992, " Electrocomposite coating of partially stabilized zirconia dispersed in a nickel matrix.”J. Mater. Sci. Lett., 11, 449-451

[10] Qu N.S, Zhu D, Chan K.C, 2006, “ Fabrication of Ni-CeO nanocomposite by Electrodeposition." Scripta Mater., 54,

\section{$1421-1425$}

[11] Gomez E, Pane S, Valles E, 2005, “ Electrodeposition of Co-Ni and $\mathrm{Co}-\mathrm{Ni}-\mathrm{Cu}$ systems in sulphate-citrate medium." Electrochim. Acta, 51, 146-153

[12] Wang L, Gao Y, Xue Q, Liu H, Xu T, 2005, "Microstructure and Tribological properties of electrodeposited Ni-Co alloy deposits.” Appl. Surf. Sci., 242, 326-332

[13] Wang W, Guo H.T, Gao J.P, Dong X.H, Qin Q.X, 2000, "XPS, UPS and ESR studies on the interfacial interaction in Ni-ZrO2 composite plating.”J. Mater. Sci., 35, 1495-1499

[14] Setare E, Raeissi K, Golozar M.A, Fathi M.H, 2009, “The structure and corrosion barrier performance of nanocrystalline zirconia electrodeposited coating." Corros. Sci., 51, $1802-1808$

[15] Valov, Stoychev D, Marinova Ts, 2002, “ Study of the kinetics of process during electrochemical deposition of zirconia from nonaqueous electrolytes." Electrochim. Acta, $47,4419-4431$

[16] Stoychev D, Ikonomov J, Robinson K, Stefanov P, Stoycheva M, Marinova Ts, 2000, "Surf. Interface Anal., 30, 69-73

[17] Rajiv E.P, Annamalai V.E, Seshadri S.K, 1992, "Transformation - toughened cobal - partially stabilized zirconia electrocomposite coating," J. Mater. Sci., 11, 466-468

[18] Benea L, Lakatos-Varsanyi M, Maurin G, 'The Annals of Dunarea De Jos' University of Galati Fascicle IX Metallurgy and Materials Science, ISSN 1453-083X NR.II- 2003,10-17

[19] Zhang K.F, Ding S, Wang G.F, 2008, "Different superplastic deformation behaviour of nanocrystalline $\mathrm{Ni}$ and $\mathrm{ZrO}_{2} / \mathrm{Ni}$ nanocomposite.” Mater. Lett., 62, 719-722

[20] Hou F, Wang W, Guo H, 2006, "Effect of the dispersibility of $\mathrm{ZrO}_{2}$ nanoparticles in $\mathrm{Ni}-\mathrm{ZrO}_{2}$ electroplated nanocomposite coatings on the mechanical properties of nanocomposite coatings.” Appl. Surf. Sci., 252, 3812-3817

[21] Wang, Hou F-Y, Wang H, Guo H-T, 2005, "Fabrication and characterization of $\mathrm{Ni}-\mathrm{ZrO}_{2}$ composite nano-coatings by pulse electrodeposition." Scripta Mater., 53, 613-618

[22] Moller A, Hahn H, 1999, "Synthesis and Characterization of Nanocrystalline $\mathrm{Ni} / \mathrm{ZrO}_{2}$ composite coating." NanoStruct. Mater., 12, 259-262

[23] Reddy B.S.B, Das K, Datta A.K, Das S, 2008, "Pulsed co-electrodeposition and characterization of Ni-based nanocomposites reinfroced with combustion-synthesized, undoped, tetragonal- $\mathrm{ZrO}_{2}$ particulates." Nanotech., 19, 15603115613

[24] Ramesh Bapu G.N.K, Jayakrishnan S, 2006, “Oxidation characteristics of electrodeposited nickel-zirconia composites at high temperatures." Mat. Chem. Phys., 96, 321-325

[25] Zhang J, Wang D.-Y, Sun Z.-F, Zhao W.-L, Guo X.-Y, "Wuhan Ligong Daxue Xuebao/J.Wuhan Univ. Tech., 2008, 30: 21

[26] H Klung, L Alexander, "X-ray Diffraction Procedures for Polycrystalline and Amorphous materials", 618 John Wiley, New York (1974) 
[27] Srivastava M, William Grips V.K, Rajam K.S, 2007, "Electrochemical deposition and Tribological behaviour of $\mathrm{Ni}$ and Ni-Co metal matrix composites with SiC nano-particles." Appl. Surf. Sci., 253, 3814-3824

[28] S.W Banovic, B.F Levin, J.N DuPont, A.R Marder, 'Progress Report prepared for U S Department of Energy under Grant No. DE-FG22-95PC95211', Project Period: 7/14/95$12 / 31 / 97$
[29] Srivastava M, William Grips V.K, Rajam K.S, 2009, "Influence of Co on $\mathrm{Si}_{3} \mathrm{~N}_{4}$ incorporation in electrodeposited Ni." J. Alloy Compd., 469, 362-365

[30] Srivastava M, EzhilSelvi V, William Grips V.K, Rajam K.S, 2006, "Corrosion resistance and microstructure of electrodeposited nickel-cobalt alloy coatings." Surf. Coat. Tech., 201, 3051-3060 